\title{
Filing for workers' compensation among Ontario cases of mesothelioma
}

\author{
Jennifer Isabelle Payne $\mathrm{PhD}^{1,2,3}$, Erin Pichora $\mathrm{MSc}^{4}$
}

\begin{abstract}
JI Payne, E Pichora. Filing for workers' compensation among Ontario cases of mesothelioma. Can Respir J 2009;16(5):148-152.
\end{abstract}

BACKGROUND/OBJECTIVE: For many types of cancer, disease attribution to occupational exposures is difficult. Mesothelioma, however, is a 'sentinel' occupational cancer associated with asbestos exposure. The present study linked workers' compensation claims data with cancer registry data to explore the completeness of reporting of mesothelioma to the Ontario Workplace Safety and Insurance Board (WSIB) according to characteristics of cases diagnosed among Ontario residents.

METHODS: Two data sources were linked at the person level: the WSIB Occupational Disease Information and Surveillance System and the Ontario Cancer Registry. Filing rates were calculated as the proportion of Ontario Cancer Registry mesothelioma cases (International Classification of Diseases - Oncology code 905) that linked to a WSIB-filed cancer claim. Filing rates were calculated for the period 1980 to 2002, and trends were calculated by year, age and county of residence at diagnosis.

RESULTS: The filing rate for compensation has increased little over the past 20 years, reaching a high of $43 \%$ in 2000 . Overall, filing rates were highest among pleural mesothelioma cases among men (range $27 \%$ to $57 \%$ ). Filing rates were highest among individuals 50 to 59 years of age and declined substantially throughout the retirement years. There was substantial variation in filing rates by area of residence, with the highest rate being in Lambton County, Ontario.

CONCLUSION: The filing rate for compensation in Ontario was much lower than the estimated proportion of cases eligible for compensation. The increased filing rate in Lambton County was likely related to this community's awareness of the association between asbestos and mesothelioma. Physicians can play an important role in educating patients of their potential entitlement to compensation benefits.

Key Words: Mesothelioma; Neoplasms; Occupational disease; Workers' compensation

\section{Les réclamations d'indemnisation d'accidentés du travail parmi les cas de mésothéliome en Ontario}

HISTORIQUE ET OBJECTIF : Dans de nombreux types de cancer, il est difficile d'attribuer la maladie à une exposition professionnelle. Cependant, le mésothéliome est un cancer professionnel « sentinelle » associé à l'exposition à l'amiante. La présente étude liait les données liées aux réclamations d'indemnisation d'accidentés du travail aux données des registres du cancer afin d'explorer l'exhaustivité des déclarations de mésothéliomes à la Commission de la sécurité professionnelle et de l'assurance contre les accidents du travail (CSPAAT) de l'Ontario, conformément aux caractéristiques des cas diagnostiqués chez les habitants de l'Ontario.

MÉTHODOLOGIE : Deux sources de données étaient liées sur le plan personnel : la CSPAAT et le Registre d'inscription des cas de cancer de l'Ontario. On a calculé les taux de réclamation d'après la proportion de cas de mésothéliomes dans le Registre d'inscription des cas de cancer de l'Ontario (Classification internationale des maladies, Oncologie, code 905) liés à une réclamation de cancer déposée auprès de la CSPAAT. On a calculé les taux de réclamation entre 1980 à 2002, et on a calculé les tendances selon l'année, l'âge et le pays de résidence au moment du diagnostic.

RÉSULTATS : Le taux de réclamations a peu augmenté depuis 20 ans, atteignant un pic de $43 \%$ en 2000. Dans l'ensemble, les taux de réclamations étaient plus élevés dans les cas de mésothéliome pleural chez les hommes (plage de $27 \%$ à $57 \%$ ). Les taux de réclamation étaient les plus élevés chez des personnes de 50 à 59 ans et fléchissaient considérablement après le départ à la retraite. On remarquait une variation importante des taux de réclamation selon la région de résidence, le taux le plus élevé s'observant dans le comté de Lambton, en Ontario. CONCLUSION : Le taux de demandes de réclamation en Ontario était beaucoup plus faible que la proportion estimative de cas admissibles à une indemnisation. Le plus fort taux de réclamation dans le comté de Lambton était probablement attribuable à la meilleure sensibilisation de cette collectivité à l'association entre l'amiante et le mésothéliome. Les médecins peuvent jouer un rôle important pour informer les patients de leur droit potentiel à une indemnisation.
$\mathrm{P}$ revious studies have demonstrated the value of comparing and/or combining administrative occupational databases with cancer registries for the purposes of surveillance and research $(1,2)$. Cancer registries contain information regarding cases of diagnosed cancer but generally lack occupational exposure data, while databases maintained by provincial workers' compensation boards generally under-report workrelated cancers but have workplace exposure data. One such study, performed in the 1980s, compared aggregate data from provincial registries and provincial compensation boards and suggested that the proportion of possible occupational cancers reported to workers' compensation boards was as low as $10 \%$ (1).

Although attributing cancer to occupational exposures is difficult, mesothelioma is considered to be a 'sentinel' occupational cancer. Mesothelioma is a rare and highly fatal morphologically defined cancer that arises in surface serosal cells lining various body cavities; the pleura is the most common site accounting for approximately $90 \%$ of all mesotheliomas, followed by the peritoneum (6\% to $10 \%$ ). Less common sites include the pericardium, the tunica vaginalis of the testes and the ovaries (3). Diagnosing mesothelioma is challenging, and current treatment options are limited and usually performed with palliative rather than curative intent. The median survival time is approximately one year from the date of diagnosis (4).

This highly fatal cancer is also largely preventable, occurring almost exclusively in workers exposed to asbestos. Indeed, the strongest and most common risk factor for mesothelioma is occupational exposure to asbestos. It has been estimated that a minimum of $65 \%$ of all mesothelioma cases, and $85 \%$ to $90 \%$ of male pleural mesothelioma cases can be attributed to occupational asbestos exposure (3). Mesothelioma incidence rates,

${ }^{1}$ Cancer Care Nova Scotia; ${ }^{2}$ Department of Diagnostic Radiology; ${ }^{3}$ Department of Community Health and Epidemiology, Dalhousie University,

Halifax, Nova Scotia; ${ }^{4}$ Population Studies and Surveillance, Cancer Care Ontario, Toronto, Ontario

Correspondence: Ms Erin Pichora, Cancer Care Ontario, 505 University Avenue, 14th floor, Toronto, Ontario M5G 1 X4.

Telephone 416-971-9800 ext 1147, fax 416-971-6888, e-mail pichora@cancercare.on.ca 
therefore, reflect trends in past occupational exposure to asbestos, for which latency of disease development is in the order of 20 to 40 years after the first exposure $(3,4)$. In addition to the asbestos mining industry, there are other industries in which workers may have been, or can now be, exposed to asbestos, including manufacturing, construction and transportation. Given the high attributable risk for mesothelioma associated with occupational asbestos exposure, it is expected that a higher proportion of diagnosed mesothelioma cases would file for workers' compensation compared with any other form of cancer.

The present study used two data sources, namely, the Workplace Safety and Insurance Board of Ontario (WSIB) Occupational Disease Information and Surveillance System (ODISS), and the Ontario Cancer Registry (OCR), and linked them at the person level. The present study had two objectives: to determine the success rate of linking the WSIBODISS database with the OCR, as part of exploring the feasibility of ongoing linkages between these two databases, and to describe the patterns of claims filed for mesothelioma to the WSIB as a function of the disease incidence in Ontario, as a measure of completeness of reporting of potentially workrelated mesothelioma.

\section{Data sources and linkage}

\section{METHODS}

The WSIB currently insures approximately $75 \%$ of the Ontario labour force against work-related injuries and disease through employer insurance (5-7). Affected workers can file claims for occupational disease for benefits ranging from income replacement, through extended health care benefits to survivor benefits. Occupational disease claims can be filed with the WSIB even after the death of the affected individual - there is no time restriction (ie, time from date of diagnosis to date of filing) for filing a claim. The ODISS database was created circa 1987 and contains data on all claims filed with the WSIB for occupational disease, including those filed before 1987 (retroactively entered from electronic and paper records). All disease claims that met the following criteria were extracted for linkage: having a diagnosis code (either fatal or nonfatal) indicating a neoplasm in any part of the body (International Classification of Diseases [ICD] - Ninth Revision [codes 140 to 239]); and a filing date on or before March 31, 2004. The variables extracted for these records included those pertaining to the worker, the administration of the claim, the cancer diagnosis and the exposure history.

The OCR is a population-based registry covering the entire province of Ontario since 1964, and is operated by Cancer Care Ontario. It is a passive registry that relies on four major sources of data: hospital separations with cancer listed as one of the diagnoses, pathology reports with a mention of cancer (available since 1980), death certificates in which cancer was the underlying cause of death, and reports on patients referred to the Princess Margaret Hospital (Toronto, Ontario) as well as regional cancer centres. It should be noted that all source records (except for death records) allow for reporting of both a cancer site coded according to the ICD-9 or ICD-10, and morphology coded according to the ICD for oncology (ICD-O). Measures of data completeness and data validity have been performed in a manner similar to the Surveillance,
Epidemiology, and End Results (SEER) system of classifying disagreement (8). An algorithm referred to as 'case resolution' is used to combine these four data sources to produce the OCR 'incident file'. When discrepancies arise between sources of information, the algorithm assigns priority to particular sources of data as well as to cancer site over morphology, producing what is referred to as 'resolved site' and 'resolved morphology'. It is this incident file that forms the basis of cancer reporting for Ontario residents dating back to 1964. Also, a 'nonincident file' exists, which contains a minimal amount of similar information on cancers that do not meet these criteria for reporting on Ontario residents (eg, Ontario resident diagnosed out of province, cancer diagnosed before 1964, nonreportable skin cancers). Variables used from both the incident and nonincident files of the OCR included demographic data and cancer diagnosis information.

Under the terms of research agreements with both the OCR and the Ontario WSIB, a nominal data file of all claims (as described above) was produced at the WSIB and sent to Cancer Care Ontario for linkage. The data file was linked with both the 'incident file' and 'nonincident file' of the OCR, using a combination of both deterministic and probabilistic linkage methods applied to last name, first name, date of birth and sex. Linked records that required resolution were resolved by the person responsible for the linkage, without the involvement of any member of the project team or the manager of the ODISS database, to ensure that the data from one data custodian (WSIB) was not shared with the other custodian (OCR).

Once linked, identifying information was removed and the resulting anonymous analytical file was stored with restricted access and subsequently prepared for analysis.

\section{Analysis}

The success of the linkage was evaluated by determining the proportion of successful links between the OCR and the ODISS in two ways - first, in cases for which all ODISS claims with one or more diagnoses of a neoplasm were linked to the OCR and, second, in cases for which ODISS claims accepted for compensation of a mesothelioma diagnosis were linked to the OCR. To calculate these proportions, successful links were divided by the total number of ODISS records for which linkage was attempted. It should be noted that, for the attempt to link all ODISS records listing a neoplasm, not all records were expected to link to the OCR. Specifically, claims listing a benign neoplasm or nonmelanoma skin cancer, claims rejected on the basis of an unconfirmed cancer diagnosis and claims from individuals diagnosed out of province or within Ontario before 1964 would not be expected to link to the OCR.

The filing rate was calculated as the proportion of mesothelioma cases diagnosed among Ontario residents from the OCR that linked to an ODISS claim record for that same individual for any type of neoplasm. Following the examination of various operational definitions of mesothelioma in the OCR and ODISS, Ontario mesothelioma cases were defined as incident cases having a resolved morphology of mesothelioma (ICD-O morphology code 905) and matching ODISS cases were defined as linking to the incident mesothelioma case regardless of adjudication status or neoplasm being claimed. This method of selecting cases with higher quality diagnostic information (ie, morphologically defined mesothelioma cases 


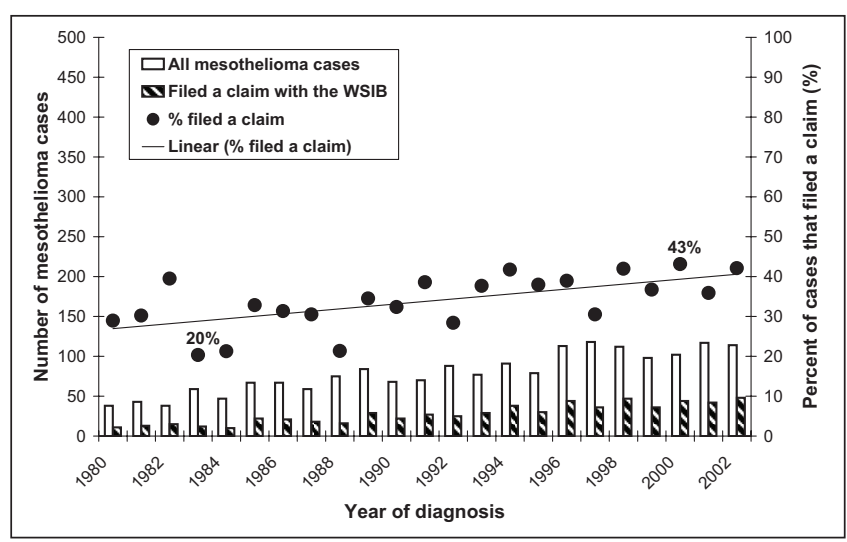

Figure 1) Time trend in the workers' compensation filing rate for mesothelioma in Ontario from 1980 to 2002. WSIB: Workplace Safety and Insurance Board of Ontario

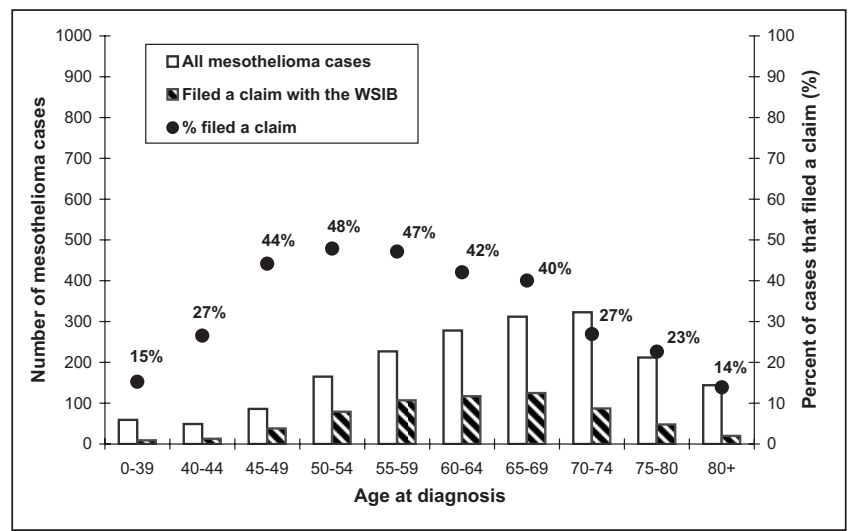

Figure 2) Age trend in the workers' compensation filing rate for mesothelioma in Ontario from 1980 to 2002. WSIB: Workplace Safety and Insurance Board of Ontario

from the OCR) for the denominator, combined with a broad definition for the numerator, was used to maximize the calculated value for the filing rate.

Given the incomplete morphology data in the OCR before 1980, analyses were restricted to between 1980 and 2002 . Diagnostic agreement was explored for these linked cases. Time trends in filing were calculated, as well as the trends in the age at filing the claim and the place of residence at diagnosis (ie, county of residence based on the standard geographical classification from Statistics Canada).

The study protocol was approved by the Research Ethics Board of the University of Toronto (Toronto, Ontario).

\section{RESULTS}

Restriction of the ODISS records to claims for neoplasms resulted in an ODISS dataset for linkage of 6499 records. The linkage of the 6499 ODISS records to both the incident and nonincident files of the OCR resulted in a linkage rate of $86 \%$ (5604 of 6499). Restricting this OCR-ODISS linkage to ODISS claims compensated for mesothelioma linking to any OCR cancer record resulted in a linkage rate of 93\% (767 of 821). Of the remaining 54 ODISS mesothelioma claims that did not link, the claim filing date for three of the claims suggested a diagnosis date before the establishment of the OCR in

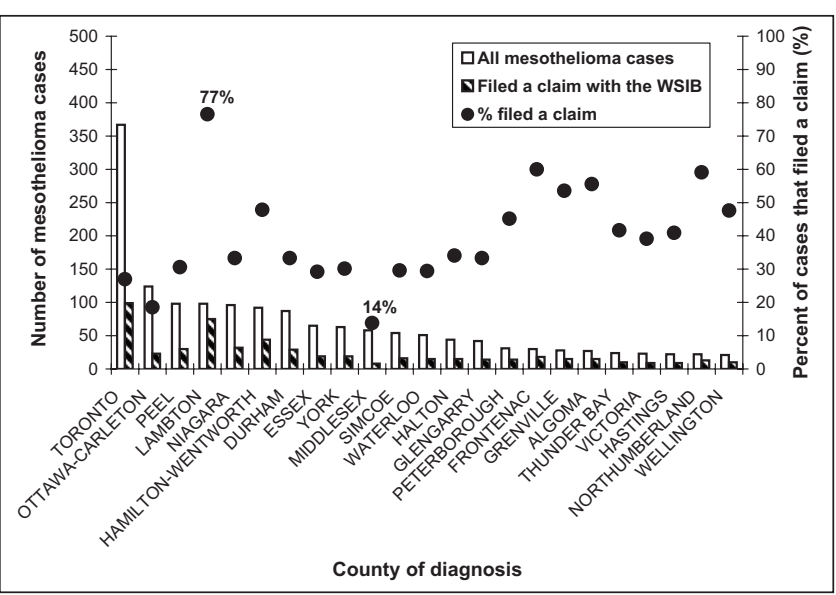

Figure 3) Place of diagnosis trend in the workers' compensation filing rate for mesothelioma in Ontario from 1980 to 2002. WSIB: Workplace Safety and Insurance Board of Ontario

1964. Further restriction of this linkage to ODISS-compensated mesothelioma claims linking to only OCR mesothelioma cases (ICD-O code 905 ), resulted in a linkage rate of 75\% (618 of 821). Of these 618 , however, nine cases were diagnosed either out of province or before 1964 and, therefore, would not appear in the OCR incident file.

Between 1980 and 2002, 1855 mesothelioma cases were diagnosed in Ontario and registered in the OCR (ICD-O code 905); of these, 643 (35\%) filed a WSIB claim with a diagnosis code of neoplasm. Of these 643 ODISS neoplasm claims, 97.5\% were filed for mesothelioma, $1.4 \%$ were filed for lung cancer and only two claims were filed listing other disease codes.

As shown in Figure 1, the rise in the absolute number of mesothelioma cases diagnosed in Ontario was paralleled by a small increase in the linear trend of the filing rate, with a range in filing rate of $20 \%$ to $43 \%$. A more detailed analysis of this filing rate revealed that the figures were much higher for pleural mesothelioma cases among men, 44\% overall and ranging from $27 \%$ to $57 \%$ throughout the 20 -year period. Filing rates are shown by age group in Figure 2, highlighting that the filing rate was much higher among cases diagnosed before retirement than after retirement, although a large proportion of cases were, in fact, diagnosed in individuals older than 65 years of age. Finally, Figure 3 highlights the substantial variation in filing rates by county of residence at diagnosis. By far, the highest filing rate was observed in Lambton County (77\%), where the age-adjusted incidence rate is approximately four times that of all of Ontario combined (Cancer Care Ontario [Ontario Cancer Registry, 2004]).

\section{DISCUSSION}

Overall, the present study demonstrated the feasibility of linking the WSIB-ODISS database with the OCR, while at the same time identifying limitations of these two sources of mesothelioma data in Ontario. In total, there were 821 WSIBODISS claims for mesothelioma receiving compensation, of which 93\% linked to an Ontario cancer case registered in the OCR, and 74\% linked specifically to an Ontario mesothelioma case registered in the OCR. Claims attributable to asbestos exposures within Ontario but diagnosed out of province would account for a portion of the $7 \%$ of claims that did not link to 
an OCR-registered case. The remaining 19\% of mesothelioma claims that linked to an OCR case not registered specifically as mesothelioma (ie, ICD-O code 905) suggests that there is some misclassification or miscoding of ODISS mesothelioma claims or of OCR mesothelioma cases. Indeed, under-reporting of mesothelioma in the OCR is known to occur primarily because the OCR algorithm used to summarize information from multiple source records relies heavily on cancer site coding, rather than morphology coding. For this reason, the OCR is susceptible to undercounting morphologically defined cancers such as mesothelioma. Reliance on cancer site data also diminishes the role of death records, given the lack of morphology information in this data source. With the introduction of ICD-10 coding on death certificates in 2000, this problem should be eliminated and work is ongoing at Cancer Care Ontario to improve other aspects affecting the completeness of registration for mesothelioma in Ontario.

By studying claims submitted to workers' compensation boards across Canada, it has been speculated that less than $10 \%$ of all cases of occupational cancer are compensated, due mainly to under-reporting as opposed to claims being rejected (1). The present study focused on a sentinel occupational cancer - mesothelioma - known to be caused by asbestos exposure, and, therefore, it would be expected that the filing rate, if not the compensation rate, would be substantially higher than $10 \%$. The present study, as well as other Canadian studies, report a filing rate higher than 10\%; however, the observed rates are still well below expected rates based on the established disease attribution to occupational asbestos exposure. For the period between 1980 and 2002, the present study found a filing rate of $35 \%$ for Ontario mesothelioma patients. In British Columbia, preliminary results from a similar linkage study (9) yielded an overall mesothelioma compensation rate of $33 \%$. In both Ontario and British Columbia, higher filing and compensation rates, respectively, were found for pleural mesothelioma than with the other mesothelioma primary sites. In Quebec, however, a linkage study of pleural mesothelioma cases with a confirmed diagnosis (ie, investigated but not necessarily compensated by the workers' compensation board) for the period between 1982 and 1996 found an exceptionally low filing rate of $22 \%$ (2).

In terms of eligibility for workers' compensation in Ontario, mesothelioma is listed as a schedule 4 disease in the Ontario Workplace Safety and Insurance Act, meaning that for workers whose employment history includes a scheduled process, the presumption of work-relatedness is irrefutable and compensation is essentially automatic. Furthermore, insured workers exposed to asbestos through nonscheduled processes are also eligible for (and have received) compensation, but claims filed by these workers are adjudicated on a case-by-case basis. In fact, more than $85 \%$ of the mesothelioma cases that filed for workers' compensation in Ontario between 1980 and 2002 were compensated.

There are several reasons why a mesothelioma patient diagnosed in Ontario might not be eligible to receive compensation from the WSIB. First, mesothelioma patients exposed to occupational asbestos in Ontario may not be WSIB-insured (currently, the WSIB insures approximately $75 \%$ of the Ontario workforce). Labour force participants not covered include individuals who are self-employed, casual workers and those employed in specific industries such as dentistry, barbering and the majority of finance and insurance companies (5-7). Although, given the nature of these industries, it is likely that most asbestos-exposed workers would be employed in a sector insured by WSIB. Second, mesothelioma patients diagnosed in Ontario may have been exposed while working out of province. Third, mesothelioma is not always attributable to workplace asbestos exposure. For example, patients exposed to asbestos through contact with an asbestos worker (eg, wife exposed to asbestos fibres from her husband's work clothing) or through an environmental source are not eligible to receive workers' compensation from the WSIB. There is evidence that these environmental exposures to asbestos may be more frequent than previously understood (10-13).

These restrictions regarding compensation eligibility, however, by no means account entirely for the extremely low rate of filing for mesothelioma observed in Ontario and elsewhere in Canada. In addition to these requirements for compensation eligibility, it is possible that the short lifespan of individuals following a mesothelioma diagnosis would make it less likely for a claim be filed (ie, after death). However, families or dependants may apply on the person's behalf even after death, for entitlement to survivor benefits and, therefore, this should not be a reason for a reduced filing rate.

Although asbestos mining ended many years ago in Ontario, and asbestos use in manufacturing is much more strictly regulated than it was in the past, exposure to asbestos is still possible. In particular, if proper remediation processes are not followed (eg, building demolition/renovation) or if workers are unaware of the potential for the presence of asbestos, exposure may exceed safe levels. Furthermore, given that the latency of disease development is approximately 20 to 40 years, Ontario residents exposed to high levels of asbestos in the past may still be at risk for developing mesothelioma. For these reasons, there is evidence that the burden of mesothelioma will continue to rise in Ontario as it has in many other jurisdictions, reflecting a legacy of exposures as long as 20 to 40 years (14-21). It is not yet clear whether the epidemic has 'peaked' in Ontario, but what is clear is that the filing proportion has changed very little in the past 20 years despite our knowledge of the relationship between asbestos exposure and mesothelioma. This has resulted in a larger number of people and their families potentially being denied supplementary health care, income replacement and survivor benefits to which they are entitled.

Different jurisdictions have approached the dilemma of low filing rates in different ways. As a result of a provincial review in Quebec, mesothelioma was made a notifiable disease in 2003, implying that physicians who diagnose a case of mesothelioma are expected to report that case to the provincial health authorities, as is done for several types of infectious disease (22). As of 2005, a partnership between the British Columbia Cancer Agency and WorkSafeBC (the British Columbia workers' compensation board) has resulted in the British Columbia Cancer Registry being used to notify physicians of newly diagnosed cases and the potential eligibility of their patient and the patient's family to receive workers' compensation benefits. Printed material is sent to the physicians along with a cover letter, with information on how to file a claim for compensation (9). In France, the National Mesothelioma Surveillance Program (23) was launched across several districts 
in 1998, to estimate the burden of mesothelioma and to generate data for both surveillance and research purposes. Of the pleural mesothelioma cases investigated as part of this program, $62 \%$ applied for compensation, which was awarded in $91 \%$ of the cases.

Cancer Care Ontario, the data custodian of the OCR, is considering the potential of developing a 'notification' system similar to that in British Columbia. The success of the linkage process in the present study, in terms of the ability to link to identifying information available in both databases, indicates that such a linkage could be used to evaluate any future intervention aimed at increasing the workers' compensation filing rate for mesothelioma. The results of the present study show that the filing rates were highest for people diagnosed before retirement, a period in which both the workplace and organized labour can help support the worker in filing for benefits. However, for a large proportion of patients who are diagnosed after retirement, physicians can play a key role in assisting them to apply for any benefits to which they may be entitled. It is believed that the high rate of filing in Lambton County is a result of the community's high level of awareness of the

\section{REFERENCES}

1. Teschke K, Barroetavena MC. Occupational cancer in Canada: What do we know? Can Med Assoc J 1992;147:1501-7.

2. Lebel G, Gingras S, Lévesque B. Analyse de l'appariement des cas de mesothelioma de la plèvre et de cancer de poumon diagnostiqués par la CSST et par l'Institut Armand-Frappier avec le Fichier des tumeurs du Québec, MSSS. Beauport: Unité de recherché en santé publique, Centre de recherché du CHUL, 2001.

3. Boffetta P, Stayner L. Pleural and Peritoneal Neoplasms, in: Schottenfeld D, Fraumeni JF, eds. Cancer Epidemiology and Prevention, 3rd edn. New York: Oxford University Press, 2006.

4. Robinson BW, Musk AW, Lake RA. Malignant mesothelioma. Lancet 2005;366:397-408.

5. Ontario Workplace Safety and Insurance Board (WSIB). Coverage under the Ontario Workplace Safety and Insurance Act. 2002 ON, WSIB.

6. Statutes of Ontario. Workplace Safety and Insurance Act: Chapter 16, Schedule A. 1997 ON, Government of Ontario.

7. Smith PM, Mustard CA, Payne JI. Methods for estimating the labour force insured by the Ontario Workplace Safety \& Insurance Board: 1990-2000. Chronic Dis Can 2004;25:127-37.

8. Holowaty EJ. The Ontario Cancer Registry. In: Black RJ, Simonato L, Storm HH, Demaret E, eds. Automated Data Collection in Cancer Registration. Lyon: 1998.

9. Kirkham TL, Demers PA, McLeod C, Tamburic L, Koehoorn M. Factors related to compensation of mesothelioma in British Columbia. $19^{\text {th }}$ International Conference on Epidemiology in Occupational Health. <http://www.chspr.ubc.ca/files/ publications/2007/mesothelioma-epicoh.pdf> (Version current at March 25, 2009).

10. Bourdes V, Boffetta P, Pisani P. Environmental exposure to asbestos and risk of pleural mesothelioma: Review and meta-analysis. Eur J Epidemiol 2000;16:411-7.

11. Luce D, Bugel I, Goldberg P, et al. Environmental exposure to tremolite and respiratory cancer in New Caledonia: A case-control study. Am J Epidemiol 2000;151:259-65.

12. Magnani C, Dalmasso P, Biggeri A, Ivaldi C, Mirabelli D, Terracini B. Increased risk of malignant mesothelioma of the pleura importance of asbestos, given that Lambton County's mesothelioma rates are well above the provincial average. Until such a system is in place, an increased awareness of the role of occupational asbestos exposure in the development of mesothelioma on the part of family physicians and various specialists can play a significant role in increasing the workers' compensation filing rate for patients by informing a newly diagnosed patient and his or her family, of the potential for compensation.

ACKNOWLEDGEMENTS: The authors acknowledge Carol Luce, Glen Farr, Claire-Marie Fortin and Alice Peter from the Ontario Workplace Safety and Insurance Board (Toronto, Ontario), Paul Demers from the University of British Columbia (Vancouver, British Columbia), as well as Bo Green, Loraine Marrett and Bronwen Waller from Cancer Care Ontario (Toronto, Ontario), for their assistance with this project. This work was supported by the Occupational Cancer Research and Surveillance Project, which was jointly sponsored by Cancer Care Ontario and the Workplace Safety and Insurance Board.

after residential or domestic exposure to asbestos: A case-control study in Casale Monferrato, Italy. Environ Health Persp 2001;109:915-9.

13. Pan XL, Day HW, Wang W, Beckett LA, Schenker MB. Residential proximity to naturally occurring asbestos and mesothelioma risk in California. Am J Resp Crit Care Med 2005;172:1019-25.

14. Banaei A, Auvert B, Goldberg M, Gueguen A, Luce D, Goldberg S. Future trends in mortality of French men from mesothelioma. Occup Environ Med 2000;57:488-94.

15. Clements M, Berry G, Shi J, et al. Projected mesothelioma incidence in men in New South Wales. Occup Environ Med 2007;64:747-2.

16. Hodgson JT, McElvenny DM, Darnton AJ, et al. The expected burden of mesothelioma mortality in Great Britain from 2002 to 2050. Br J Cancer 2005;92:587-93.

17. Leigh J, Driscoll T. Malignant mesothelioma in Australia, 1945-2002. Int J Occup Environ Health 2003;9:206-17.

18. Marinaccio A, Montanaro F, Mastrantonio M, et al. Predictions of mortality from pleural mesothelioma in Italy: A model based on asbestos consumption figures supports results from age-period cohort models. Int J Cancer 2005;115:142-7.

19. Murayama T, Takahashi K, Natori Y, Kurumatani N. Estimation of future mortality from pleural malignant mesothelioma in Japan based on an age-cohort model. Am J Ind Med 2006;49:1-7.

20. Price B, Ware A. Mesothelioma trends in the United States: An update based on surveillance, epidemiology, and end results program data for 1973 through 2003. Am J Epidemiol 2003;159:107-12.

21. Segura O, Burdorf A, Looman C. Update of predictions of mortality from pleural mesothelioma in the Netherlands. Occup Environ Med 2003;60:50-5.

22. De Guire L, Camus M, Case B, et al. The epidemiology of asbestosrelated diseases in Quebec. Montréal: Institut national de santé publique de Québec; $2004<$ http://www.inspq.qc.ca/pdf/ publications/293-EpidemiologyAsbestos.pdf > (Version current at March 25, 2009).

23. Goldberg M, Imbernon E, Rolland P, et al. The French National Mesothelioma Surveillance Program. Occup Environ Med 2006;63:390-5. 


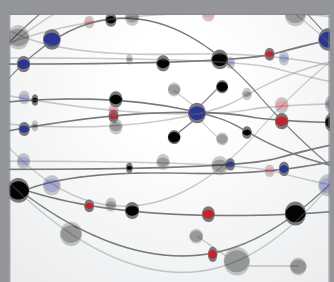

The Scientific World Journal
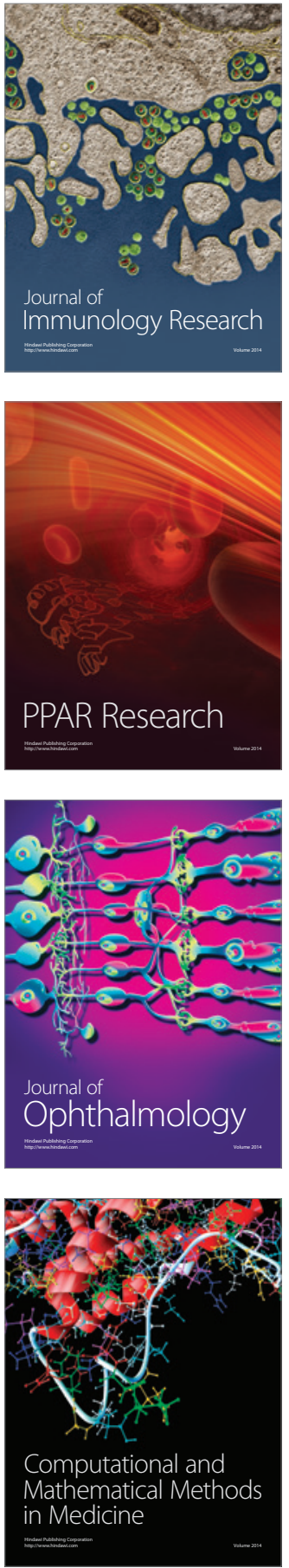

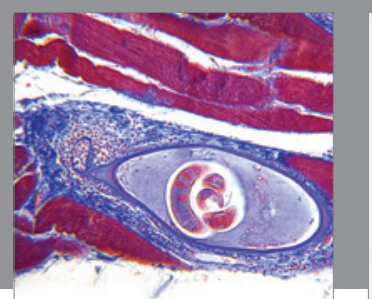

Gastroenterology Research and Practice

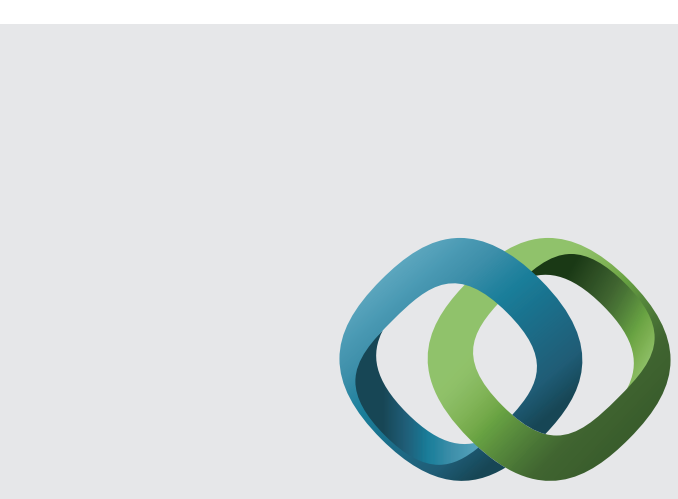

\section{Hindawi}

Submit your manuscripts at

http://www.hindawi.com
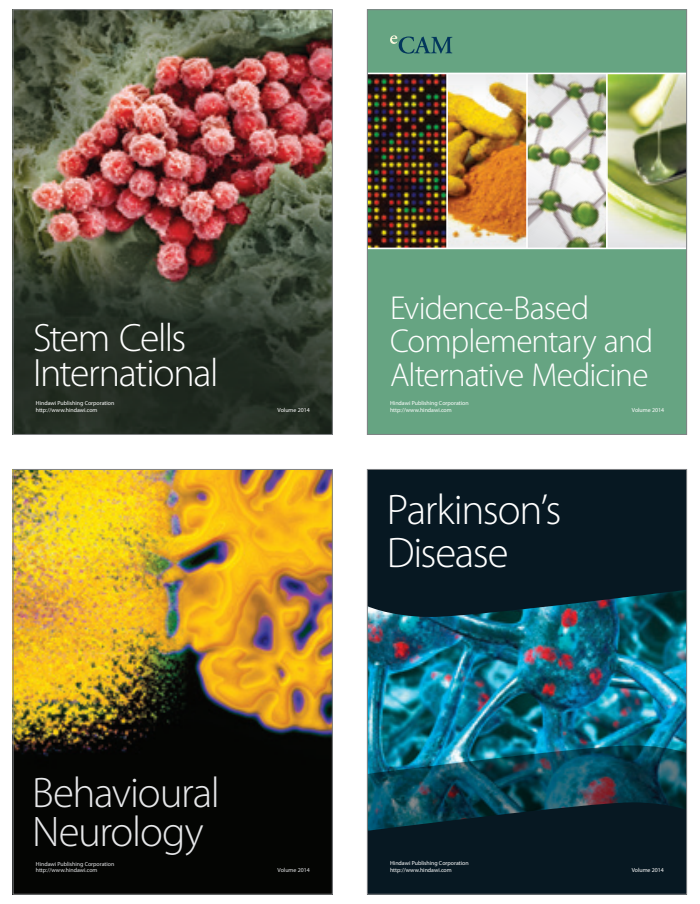
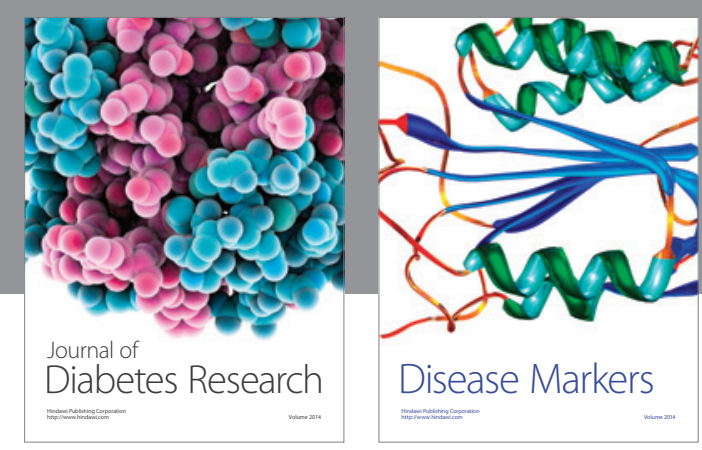

Disease Markers
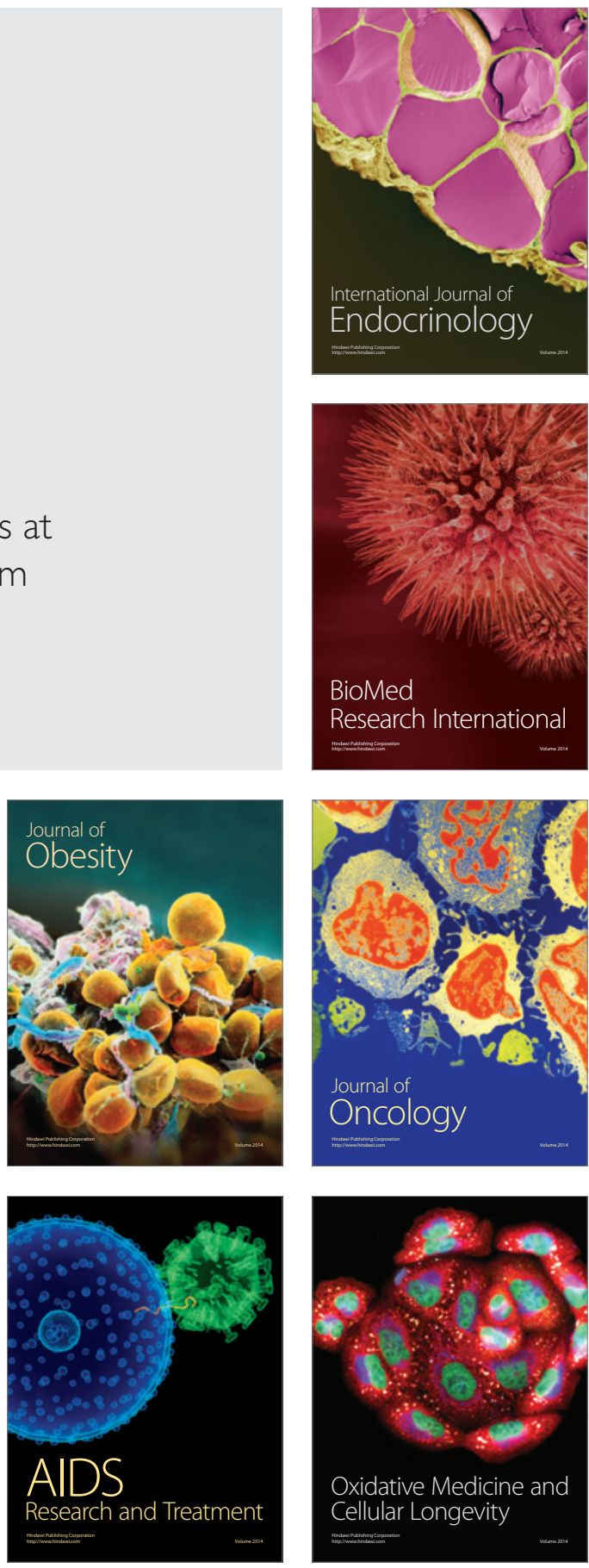